\title{
Challenges in Women with Diabetes During the COVID-19 Pandemic
}

\author{
Gagan Priya, ${ }^{1}$ Sarita Bajaj, ${ }^{2}$ Emmy Grewal, ${ }^{3}$ Indira Maisnam, ${ }^{4}$ Sruti Chandrasekharan ${ }^{5}$ and Chitra Selvan ${ }^{6}$ \\ 1. Department of Endocrinology, Fortis and Ivy Hospitals, Mohali, Punjab, India; 2. Department of Medicine, Moti Lal Nehru Medical College, \\ Prayagraj, Uttar Pradesh, India; 3. Department of Endocrinology, Max Super Speciality Hospital, Mohali, Punjab, India; 4. Department of Endocrinology, \\ R G Kar Medical College, Kolkata, West Bengal, India; 5. Department of Endocrinology, Rela Institute, Chennai, Tamil Nadu, India; 6. Department of \\ Endocrinology, Ramaiah Medical College, Bangalore, Karnataka, India
}

DOI: https://doi.org/10.17925/EE.2020.16.2.100

$\mathrm{T}$ he coronavirus disease 2019 (COVID-19) pandemic has created significant challenges for healthcare systems across the world. The disease seems to infect men and women in equal numbers, though trends suggest that men have greater morbidity. This has been attributed to differences in immunological response, expression of angiotensin-converting enzyme 2 (ACE2), prevalence of comorbidities, and health-related behaviours, such as smoking. However, this cannot be taken to mean that women are somehow protected. Advanced age, smoking, diabetes, hypertension, cardiovascular disease and chronic obstructive pulmonary disease have emerged as the leading contributors to increased morbidity and mortality from the disease. Women with diabetes form a vulnerable group as they often receive suboptimal diabetes care and support, even though they have a high burden of comorbidities and complications. While there are challenges in healthcare delivery during the pandemic, cardiometabolic care cannot be compromised, which calls for exploring new avenues of healthcare delivery, such as telemedicine. Pregnant women with diabetes should continue to receive quality care for optimal outcomes, and the psychological health of women also needs special consideration. The management of hyperglycaemia during COVID-19 infection is important to reduce morbidity and mortality from the infection. The gendered impact of outbreaks and quarantine goes beyond biomedical and psychological aspects, and the socioeconomic impact of the pandemic is likely to affect the long-term care of women with diabetes, which creates an urgent need to create effective policies and interventions to promote optimal care in this vulnerable group.

\section{Keywords}

CoVID-19, gender, women, diabetes, gestational diabetes, pregnancy with diabetes

Disclosures: Gagan Priya, Sarita Bajaj, Emmy Grewal, Indira Maisnam, Sruti Chandrasekharan and Chitra Selvan have no financial or non-financial relationships or activities to declare

in relation to this article.

Review Process: Double-blind peer review.

Compliance with Ethics: This article involves a review of the literature and did not involve any studies with human or animal subjects performed by any of the authors.

Authorship: The named authors meet the International Committee of Medical Journal Editors (ICMJE) criteria for authorship of this manuscript, take responsibility for the integrity of the work as a whole, and have given final approval for the version to be published.

Access: This article is freely accessible at

tOuchENDOCRINOLOGY.COM

(C) Touch Medical Media 2020

Received: 28 April 2020

Accepted: 26 May 2020

Published Online: 4 September 2020

Citation: European Endocrinology. 2020;16(2):100-8

Corresponding Author: Gagan Priya,

Department of Endocrinology, Fortis Hospital,

Phase 8, Mohali 160059, India.

E: gpriya77@gmail.com

Support: No funding was received in

the publication of this article.
The coronavirus disease 2019 (COVID-19) pandemic has spread rapidly to become a global health threat. The disease is caused by severe acute respiratory syndrome coronavirus-2 (SARS-CoV-2), a novel $\beta$-coronavirus that belongs to a family of enveloped RNA viruses, the coronaviruses.' While some of the coronaviruses cause common flu, other strains, such as SARS-CoV, Middle East respiratory syndrome coronavirus (MERS-COV) and now SARS-COV-2, have been responsible for outbreaks of severe acute respiratory illness.

The route of transmission is primarily via large respiratory droplets and infected fomites. The infection has a high transmissibility. SARS-CoV-2 binds to its receptor, which is now recognised to be angiotensin-converting enzyme 2 (ACE2), on the host cell via its envelope spike glycoprotein (S-protein). ${ }^{2}$ This is followed by membrane fusion and internalisation of viral genome. Following replication of the genomic RNA and synthesis of envelope glycoproteins and nucleocapsid proteins, mature virions are released from the cell. The clinical picture can vary from mild upper respiratory tract infection or detection in asymptomatic carriers, to moderate-to-severe symptoms that include lower respiratory tract infection, life-threatening pneumonia, acute respiratory distress syndrome (ARDS), cardiac injury, septic shock and multi-organ dysfunction. ${ }^{1}$

COVID-19 affects all age groups, from newborns to the elderly. ${ }^{1}$ Several risk factors may predispose the individual to increased risk of severe disease and death; these include older age, male gender, smoking and presence of underlying comorbid conditions. ${ }^{3-5}$ Of these comorbidities, diabetes, hypertension and cardiovascular disease (CVD) have emerged as the leading contributors to increased morbidity and mortality. ${ }^{3-6}$ In an early report from China, COVID-19 infected more men $(0.31 / 100,000)$ than women $(0.27 / 100,000)$, with higher mortality in men. ${ }^{6}$ However, several studies suggest women with diabetes have a greater burden of micro- and macro-vascular complications and this cannot be ignored in the light of the current pandemic.? Not only are women more vulnerable to the complications of diabetes, they have less access to healthcare and receive less support to manage diabetes compared to men. ${ }^{8}$ In addition, pregnant women are more prone to respiratory tract infections, and COVID-19 may impact maternal-foetal outcomes. ${ }^{9}$

The COVID-19 global pandemic is affecting the psychological and emotional health of people, both due to widespread fear and anxiety and the impact of social distancing. Psychological stress, limited outdoor mobility, altered lifestyle and stress eating are likely to impact glycaemic and metabolic 
control in women with diabetes, further increasing their risk. ${ }^{10} \mathrm{At}$ the same time, women are the primary caregivers and constitute a substantial proportion of the workforce in healthcare. This increases workload and responsibilities placed on women in both domestic and professional capacities, and also increases their chances of becoming infected. The response to the COVID-19 pandemic appears no different. ${ }^{11}$ The long-term socioeconomic consequences of the pandemic may also have an impact on women and further compromise the care of women with diabetes.

\section{Gender differences in the aetiology of COVID-19}

Early reports from Wuhan, China showed a male preponderance of COVID-19 infection, with 68\% of those infected being men. ${ }^{12}$ Later data from 30 provinces outside Hubei demonstrated that the male predominance was decreasing, as was the median age, with a greater proportion of young women being infected. ${ }^{13}$ Medical records of community-acquired COVID-19 infection in a Wuhan hospital of 140 patients also suggest that men and women were equally likely to contract the virus; however, the disease course was more severe in men. ${ }^{14}$ An analysis of the Chinese Center for Disease Control and Prevention (CDC) data of 72,314 cases suggested that deaths were more common in men and those above 60 years of age. ${ }^{15}$

Early in the pandemic, South Korea had the second-highest number of cases in the world, with data showing that, as of 2 March 2020,62\% of those infected were women. ${ }^{16}$ This was attributed to a higher participation of women in a religious event that was linked to early outbreak. However, $59.1 \%$ of those who died were men. ${ }^{16}$ In a retrospective analysis of 150 cases, there was a significant difference in age of the deceased versus discharged, but not sex ratio. ${ }^{17}$ In a report from another COVID-19 hospital in Wuhan, $66 \%$ of the critically ill and non-survivors were men, while $34 \%$ were women. ${ }^{18} \mathrm{~A}$ long-term nursing care facility in Washington State, USA reported 167 confirmed cases of COVID-19 - women constituted $69 \%$ of infected residents, $76 \%$ of infected healthcare personnel and $5 \%$ of infected visitors. ${ }^{19}$ In a media briefing by the Ministry of Health, India, on 6 April 2020, $76 \%$ of those infected and $73 \%$ of those deceased, were men..$^{20}$

\section{How can we explain these gender difference?}

The data so far raise very important questions. Most studies suggest that men and women may be equally affected by infection rate, but mortality is higher in men. Several explanations have been put forth, which are discussed below.

\section{The mysterious case of ACE2}

ACE2 is the receptor for SARS-COV-2 binding and entry into the host cell after priming of the S-protein by transmembrane protease serine 2 (TMPRSS2). ${ }^{2}$ ACE2 is widely expressed in the upper respiratory tract, alveolar epithelial cells in the lungs, endothelium, heart, glomerular tubules, pancreas, testis and gastrointestinal tract. ${ }^{2.21}$ Theoretically, higher expression of ACE2 could increase the risk of viral infection by increasing viral binding. ${ }^{22}$

On the other hand, ACE2 plays an important role in the cardiovascular system and is counter-regulatory to the renin-angiotensin-aldosterone system (RAS) (Figure 1). ACE2 counteracts the RAS cascade by catalysing angiotensin I and II. ${ }^{23}$ The degradation products promote vasodilatation and have anti-fibrotic and anti-inflammatory effects. ${ }^{24}$ Animal data suggest that increased ACE2 expression may have a protective effect on the lungs and cardiovascular system, and may counterbalance the effects of angiotensin II.21,23 RAS activity is increased during hypoxia and is implicated in the pathogenesis of acute lung injury, ARDS
Figure 1: The physiological role of angiotensin-converting enzyme 2

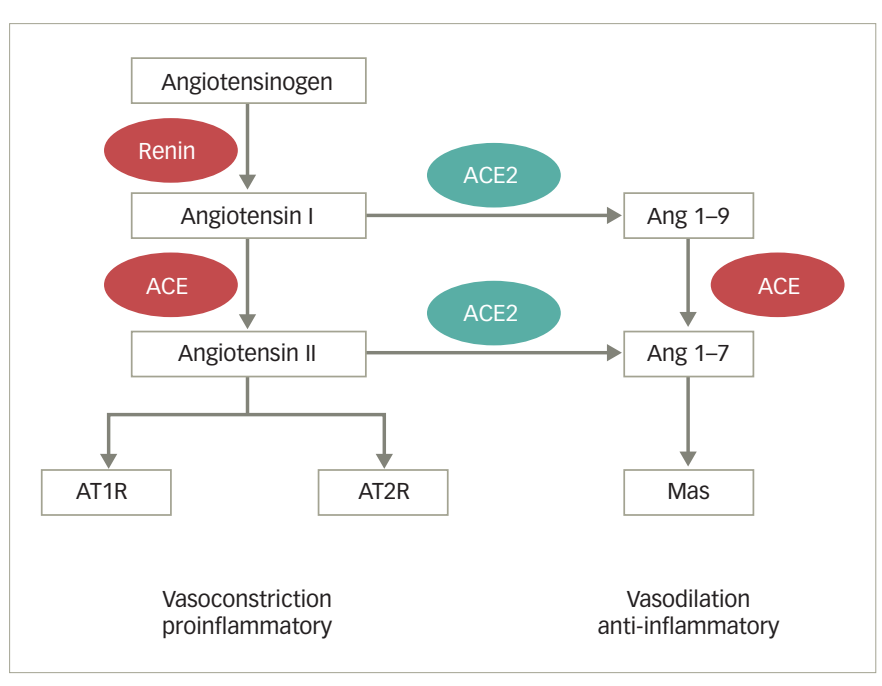

$A C E=$ angiotensin-converting enzyme; $A$ ng = angiotensin; $A T 1 R=$ angiotensin receptor 1; AT2R = angiotensin receptor 2; Mas = Mas proto-oncogene.

and cardiovascular injury, while ACE2 counteracts RAS and may be organ-protective. ${ }^{21}$

The ACE2 gene is X-linked and is differentially expressed in men and women, which has been proposed as an explanation of gender differences in susceptibility to COVID-19. ${ }^{24}$ In a study on rats, ACE2 expression in the lungs reduced with aging in both males and females. ${ }^{25}$ ACE2 expression was reported to be higher in Asian men than women and patients of other ethnicities. ${ }^{26}$ Moreover, the serine protease TMPRSS2 that is used for S-protein priming is androgen-regulated, and it is possible that its expression in alveolar epithelial cells of men may be higher, leading to greater viral replication. ${ }^{27}$ However, others have refuted this and reported that the mRNA expression of TMPRSS2 in the lungs was not higher in males versus females in either mice or humans. ${ }^{28} \mathrm{In}$ a recent study from Mumbai, 68 subjects (48 males, 20 females) with symptomatic disease were followed with serial oropharyngeal/nasopharyngeal swabs. Viral clearance was achieved earlier in females with a median difference of 2 days $(\mathrm{p}=0.038) .{ }^{29}$ The authors noted that testis, but not ovaries, have high expression of ACE2 and proposed that this may explain longer persistence of the virus in men.

To summarise, while ACE2 may be involved in viral entry and replication, higher ACE2 activity may itself be protective for the lungs and cardiovascular system. However, more research is needed to understand the complex relationship between ACE2, TMPRSS2 and COVID-19 infection. It is reassuring that several observational studies have concluded that ACE inhibitors or angiotensin receptor blockers (ARBs) are not associated with increased risk of acquiring infection, or greater morbidity and mortality. ${ }^{30-33}$

\section{Personal habits}

Smoking is more common in men than women and has been linked to an increased risk of severe COVID-19, though the evidence has not been consistent. ${ }^{34}$ According to the World Health Organization (WHO), smoking increases the contact of fingers with the lips, thereby increasing the risk of hand-to-mouth transmission. In addition, smokers may also have reduced lung capacity which adversely affects outcomes. Smoking increases the expression of ACE2 in the lungs and may also contribute to more severe disease. ${ }^{35,36}$ Smoking was also found to 
increase the expression of TMPRSS2 in lungs irrespective of gender. ${ }^{28}$ A recent meta-analysis concluded that smoking is associated with more severe progression and adverse outcomes in COVID-19. ${ }^{34}$

\section{Societal roles and exposure}

vulnerable groups are those who are disproportionately exposed to a risk. In a rapidly evolving and expanding pandemic, the face of vulnerable groups changes over time and place. Women constitute a highly vulnerable group because of societal and gender-related roles, if not due to biological factors. As the pandemic progresses, women may be at higher risk of infection as they constitute $70 \%$ of the healthcare and social sector workforce in many countries. ${ }^{37}$ In most countries, men constitute the majority of the physicians, dentists and pharmacists, while women constitute the majority of the nurses and midwives. ${ }^{37}$ Moreover, women are more likely to engage as caregivers to patients infected with COVID-19 at home or informally, often without adequate protection.

Does this imply that women have a biological advantage? To say that women are less susceptible than men to severe COVID-19 disease would be unfair. Transmission of infection occurs via airborne droplets and/or fomites from an infected person. The risk of acquiring the infection appears to be similar in both men and women. Social activities, behaviour, personal habits, population movement and comorbidities seem to be the important determinants of the disease spread.

\section{Diabetes and COVID-19 in women}

There is a high prevalence of pre-existing comorbidities in patients infected with severe COVID-19. In data from a hospital in Wuhan, $64.3 \%$ of patients had at least one comorbidity, with diabetes in $12.1 \%$ of patients. ${ }^{14}$ In a meta-analysis of 10 studies including 76,993 patients, the prevalence of hypertension was 16.37\% (95\% confidence interval [Cl] 10.15-23.65\%), CVD was $12.11 \%$ (95\% Cl 4.40-22.75\%), and diabetes 7.87\% (95\% Cl 6.57-9.28\%). ${ }^{5}$

People with diabetes have defects in innate and adaptive immunity that increase their susceptibility to infections. ${ }^{38}$ Viral clearance is also reduced in individuals with diabetes. ${ }^{38}$ Moreover, the inflammatory response to viral infections is also greater with a higher risk of cytokine storm..$^{39}$ The expression of ACE2 is increased in people with type 1 or type 2 diabetes, and by certain medications including ACE inhibitors, ARBs, ibuprofen and thiazolidinediones. ${ }^{23}$ ACE2 polymorphisms have been linked to diabetes and hypertension in Asian subjects, and this may determine a genetic predisposition to severe infection. ${ }^{40}$ Moreover, diabetes is often associated with other comorbidities including obesity, hypertension and CVD. In previous epidemics of respiratory diseases, such as H1N1, SARS and MERS, diabetes was associated with more severe disease and higher mortality risk. ${ }^{39,41}$ Emerging data for COVID-19 also clearly demonstrates that increased age, diabetes, hypertension and CVD are associated with a significant increase in morbidity and mortality and an overall poorer prognosis. ${ }^{4,7,42}$

In a nationwide analysis of 1,590 patients with COVID-19 across China, the risk factors for the composite outcome of intensive care unit (ICU) admission, need for mechanical ventilation and/or death included chronic obstructive pulmonary disease (COPD), diabetes, hypertension and malignancy. ${ }^{3}$ In a meta-analysis of six studies ( $n=1,527), 17.1 \%$ had hypertension, $16.4 \%$ had CVD and 9.7\% had diabetes. The prevalence of hypertension and diabetes was two-fold higher and that of CVD was three-fold higher in those with severe disease (ICU admission), compared with those with non-severe disease. ${ }^{4}$
Figure 2: Challenges for women with diabetes during the COVID-19 pandemic

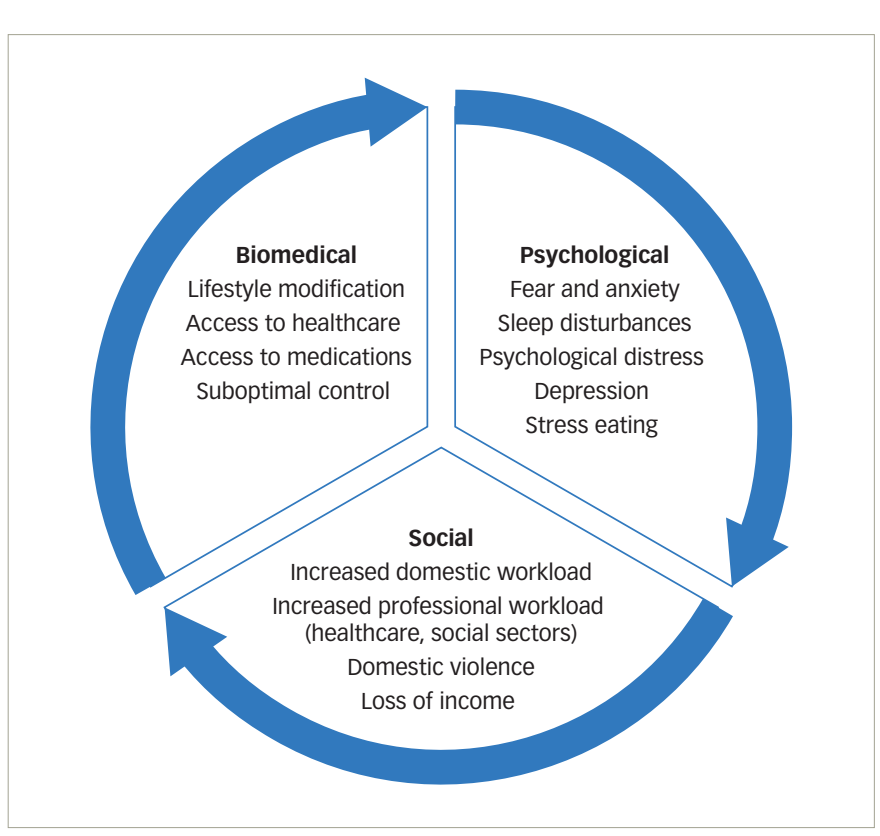

An increased risk was further reflected in an evaluation of 174 consecutive patients with COVID-19, of whom 21.2\% ( $n=37)$ had diabetes. ${ }^{43}$ Compared with people without diabetes, those with diabetes had higher risk of pneumonia; elevated markers of tissue injury such as lactate dehydrogenase, alanine aminotransferase and gamma glutamyl transferase; elevated inflammatory markers including erythrocyte sedimentation rate, C-reactive protein, interleukin-6 (IL-6) and ferritin; and greater hypercoagulability (coagulation index, fibrinogen and D-dimer). Patients with diabetes were older and had greater mortality. ${ }^{43}$ Other studies from the USA and Italy have shown similar risk of severe COVID-19 in people with diabetes. ${ }^{44,45}$

To summarise, diabetes has been recognised as a major risk factor for severity of infection and complications, such as acute lung and cardiac injury, need for hospitalisation and ICU admission, as well as mortality. Diabetes is often accompanied by comorbid conditions, such as CVD, heart failure and chronic kidney disease, that further amplify this risk. The available data so far have not explored gender differences in people with diabetes and COVID-19, but it has been widely established that women with diabetes have a greater burden of concomitant comorbidities which furthers their risk.? Therefore, women with diabetes are an important vulnerable group that needs special care.

\section{Management of diabetes in women during the pandemic}

Several challenges exist in caring for women with diabetes, even outside the timeframe of a pandemic. These include limited access to healthy food, time and space for exercise, and access to medications and healthcare facilities. Such resources are generally scarce in low- and middle-income countries (LMICS), and women bear the greater brunt of these limitations. ${ }^{8}$ This scarcity can be magnified in times of a global health crisis, such as the ongoing COVID-19 pandemic. The pandemic itself, and containment efforts, pose significant challenges for the management of women with diabetes across all domains of diabetes care (Figure 2). 


\section{Healthy food and nutrition}

There are numerous reasons why women may not consume healthy food, including being unable to cook separate meals; being offered unhealthy, processed food; lack of support from partners; time used to care for the elders and children in the family; or lack of time to make healthy food choices for themselves.46,47 The challenges are heightened when a large family lives at home, meaning managing healthy diet patterns is difficult. A healthy diet plan for the entire family would be a potential solution for this issue. Family support has a positive impact on healthy diet and increases perceived support, self-efficacy, psychological wellbeing and glycaemic control. ${ }^{48}$

\section{Exercise and physical activity}

Physical activity helps improve glycaemic control and weight, as well as assists in stress management. In addition to routine household chores, which were found to be of light-to-moderate intensity, at least 30 minutes per day (150 minutes a week) of moderate-to-high intensity physical activity daily has significant salutary effects. Some women prefer to exercise with friends; ${ }^{46}$ however, with the current scenario, it is difficult to socialise and group workouts are not possible. Given that most family members are currently at home, this could be an opportunity to engage in group family activities, including workouts.

\section{Sleep}

The importance of sleep hygiene has been emphasised in cardiometabolic health, ${ }^{49}$ as well as for improvement of immunity. ${ }^{50}$ With the pandemic and the lockdown having created significant change in daily schedules, as well as anxiety, it is important to emphasise the need for adequate sleep and avoid disrupting day-night schedules. ${ }^{49}$

\section{Access to healthcare facilities and clinic visits}

One of the major challenges of COVID-19 results from the need to minimise the chances of exposure, especially in those at high risk. Limitations on travel also pose a challenge to healthcare access. This is likely to result in the postponement of routine clinical visits or visits for seemingly minor ailments. While in-person consultation should not be deferred if the situation demands, alternate means of consultation such as telemedicine and remote consultation can be utilised to ensure continuity of care.51 Telehealth can help by positively transforming the quality and cost-effectiveness of diabetes management. Sustained improvements in glycaemic control and other clinical outcomes of diabetes via telemedicine have been reported. ${ }^{52}$ Mobile-based technology like text messages and cell-phone applications help in the self-management of diabetes.

Several countries have issued regulations regarding the use of telemedicine using text-messaging services, phone or video calls, emails or social media platforms for remote consultation. ${ }^{53}$ Telemedicine can be used to educate and monitor patients, adjust their insulin dose, and reinforce lifestyle advice. However, the Achilles heel in this situation is the patient's access to and ability to use these platforms. The platform may need to be tailored to the wishes and needs of the patient. ${ }^{54}$ Educational videos of self-monitoring of blood glucose (SMBG), insulin injection technique, hypoglycaemia recognition, and care and sick-day rules can be of great assistance. For diabetes self-management, SMBG is very useful; SMBG data can be shared with the clinician for further advice on dose titration. Laboratory investigations can be advised based on clinical judgement.

\section{Access to medications}

There has been widespread fear among the public with regards to continued supply of medications and insulin. People with diabetes should be instructed to stock up sufficient medicine supplies for at least 1-2 months and replenish it before the previous stock is over. However, panic buying should be discouraged. If there is a disruption in supply, patients should be advised to discuss alternatives with their healthcare providers. If financial constraints arise, less expensive alternatives among oral and injectable therapy need to be considered.

\section{Need for optimal cardiometabolic control}

Diabetes is associated with adverse outcomes of COVID-19. Suboptimal glycaemic control further impairs immunity and increases the risk of severe infection, super-added bacterial infections and complications in acute viral respiratory diseases. ${ }^{54,55}$ Therefore, there is an urgent need for maintenance of optimal glycaemic control. There is a lack of published literature on the risk associated with COVID-19 in those with type 1 diabetes or gestational diabetes, but it is not likely to be different from type 2 diabetes. Rather, individuals with type 1 diabetes are at a higher risk of acute hyperglycaemic emergencies and hypoglycaemia episodes. So, the need for the continued and optimised diabetes care cannot be emphasised enough.

While access to medications and the direct cost of treatment are likely to emerge as important variables in decision-making, especially in LMICs, it is important to ensure that cardiometabolic health is not compromised and evidence-based practice guidelines are followed. ${ }^{56}$ Dipeptidyl-peptidase 4 (DPP4) was the receptor for viral binding for the MERS coronavirus, ${ }^{57}$ however, SARS-COV-2 enters the cell by binding to ACE2. ${ }^{57}$ Structural studies suggest a potential interaction between SARS-CoV-2 and DPP4 receptor, and this interaction needs to be explored further. In a report from France, the rate of intubation was significantly lower in patients with diabetes who had been on DPP4 inhibitors compared with those who had not been exposed to them (81\% versus $43 \%$ ). ${ }^{30}$ Therefore, at present there should be no concern with continued use of DPP4 inhibitors. ${ }^{58}$

Concern was raised about the use of RAS blockers which may upregulate ACE2 expression. However, while soluble ACE2 has been shown to be increased slightly, this is unlikely to have a significant impact on SARS-CoV-2 entry as membrane-bound form remains unchanged. ${ }^{24}$ As discussed earlier, the relationship between ACE2 expression and severity of infection is not well understood and urgent research is needed for clear answers to this puzzle. RAS dysfunction is implicated in the pathogenesis of lung and cardiac injury in SARS-COV-2. During acute lung injury, alveolar expression of ACE2 is downregulated, leading to increased angiotensin $\|$, which results in increased membrane permeability and acute lung injury. ${ }^{21}$ It has been suggested that the continued use of RAS blockers may reduce the cardio-pulmonary risk associated with COVID-19. ${ }^{21}$ Moreover, discontinuation of RAS blockers may be detrimental in people with diabetes and CVD where RAS blockers have cardio- and reno-protective effects and reduce mortality. ${ }^{24}$ Discontinuation of ongoing therapy may lead to destabilisation of previous control and increase the risk of cardiovascular events.

Several recent studies have in fact demonstrated that the continued use of RAS blockers does not increase the risk of COVID-19 infection and may actually improve outcomes. 21,27 30-33 In data from France, the need for intubation was not different in patients exposed to ARBs or ACE inhibitors compared to those who were not on these drugs..$^{30}$ In a publication from China, including 1,128 adults with hypertension and COVID-19, of which 188 were taking ACE inhibitors or ARBS, the unadjusted mortality was actually lower in those on ACE inhibitors or ARBS (3.7\% versus 9.8\%, $\mathrm{p}=0.01$ ). ${ }^{27}$ In a meta-analysis of 14 studies reporting 19,000 COVID-19 cases, the authors did not find an increased risk with ACE inhibitor/ARB exposure. 
Table 1: Prevention of COVID-19 and precautions in women with diabetes

\begin{tabular}{|c|c|}
\hline General precautions & $\begin{array}{l}\text { - Frequent handwashing for } 20 \text { seconds or sanitising hands with a } 70 \% \text { alcohol-based rub } \\
\text { - Avoid touching the face or eyes } \\
\text { - Avoid gatherings, public transport or crowded spaces } \\
\text { - Avoid non-essential travel } \\
\text { - Maintain a distance of } 2 \text { metres from others } \\
\text { - Cover the nose and mouth with a clean tissue or flexed elbow when coughing or sneezing } \\
\text { - Thoroughly clean groceries/vegetables prior to use }\end{array}$ \\
\hline Optimised diabetes care & $\begin{array}{l}\text { - Balanced nutrition and hydration } \\
\text { - Regular physical activity } \\
\text { - Adequate sleep } \\
\text { - Stress-reduction strategies } \\
\text { - Frequent self-monitoring of blood glucose } \\
\text { - Hypoglycaemia care and sick-day guidelines } \\
\text { - Consultation with healthcare provider - consider telemedicine, and in-person visit, if deemed necessary } \\
\text { - Maintain good glycaemic control as per individualised targets } \\
\text { - Cardiovascular and renal risk assessment and optimisation } \\
\text { - Vaccination against pneumococcal pneumonia and influenza }\end{array}$ \\
\hline Precautions when visiting healthcare facility & $\begin{array}{l}\text { - Restrict the number of patients at any time to avoid overcrowding } \\
\text { - Adequate spacing between patients } \\
\text { - Screen patients at entry for flu-like symptoms and segregate them to a separate dedicated 'flu corner' } \\
\text { - Provide patients with masks and gloves at entry } \\
\text { - Use of protective gear by healthcare providers } \\
\text { - Prominently display general hygiene and social distancing instructions } \\
\text { - When using instruments such as stethoscope or sphygmomanometer, sanitise after each use }\end{array}$ \\
\hline
\end{tabular}

On the contrary, exposure to them was associated with lower risk of mortality (odds ratio [OR] 0.48, 95\% $\mathrm{Cl} 0.29-0.81, \mathrm{p}=0.006$ ). ${ }^{31}$

The American and European societies of cardiology recommend that previous antihypertensive therapy should be continued, and ACE inhibitors or ARBs should not be discontinued as there is no empirical or clinical evidence of increased risk. ${ }^{59-61}$

\section{Psychological health}

With the pandemic spreading across the globe and resulting in significant casualties, it has created a substantial burden on the psychological and emotional health of individuals. Feelings of intense anxiety, insecurity and uncertainty are further compounded by social distancing and restriction of social interactions that form the fabric of a society. Women in general are more vulnerable to psychological disorders; the reasons are not entirely clear but emotional changes to stress are more intense in women. ${ }^{62,63}$ Gender differences also exist in the processing of fear, with women showing higher reactivity of neural responses involved in fear and arousal response. ${ }^{63}$ In a questionnaire-based survey of 300 participants from Wuhan, China, the prevalence of post-traumatic stress symptoms was 7\%, with women being most affected, especially with respect to re-experiencing, negative changes in mood and cognition, and hyperarousal.62

Mental health needs remain poorly addressed during pandemics and concerted efforts are required to provide psychological support. ${ }^{64}$ Women with diabetes are a highly vulnerable group who are already coping with the demands of diabetes self-management. Psychological distress can make them more vulnerable to poor outcomes. ${ }^{65}$ While government helplines for psychological counselling have been opened, diabetes care providers have a unique opportunity to educate and empower women; allay anxiety, myths and misconceptions; motivate them; and provide psychological support. In several places, diabetes care providers are using the platform of social media to provide a safe and trustworthy source of information and promote positive health behaviour.66

While there are new problems that emerge in the management of diabetes in women at this time, it is possible to come up with creative solutions to address them.

\section{Prevention of COVID-19 among women with diabetes}

Since women with diabetes are more susceptible to severe COVID-19 infection, all efforts should be focused on the prevention of infection. This includes routine preventive measures suggested for all individuals, including those at higher risk, as well as more specific measures such as nutrition, lifestyle modification, stress management and optimised cardiometabolic control (Table 1). Crowded outdoor areas have the potential to become a source of spreading the infection and the utmost care is needed to avoid over-crowding and exploring alternate means of consultation. Telemedicine services and remote consultation offer a great opportunity to connect with patients without exposing them. However, it is important to understand that telemedicine cannot be a substitute for an in-person consultation, which should not be deferred if the need arises. Several local governing bodies have provided suggestions for the safe running of outdoor practices. ${ }^{67}$

\section{Management of diabetes in women with COVID-19}

The management of COVID-19 infection in patients with diabetes is not different from those without diabetes. However, it is important to understand that they are at a higher risk of complications and therefore, a lower threshold for hospitalisation is to be maintained.

Inadequate glycaemic control has been shown to increase the risk of severe disease and mortality in viral respiratory illnesses; in SARS, plasma glucose concentration was an independent predictor of morbidity and mortality. ${ }^{43}$ 
Table 2: Management of diabetes in patients with COVID-19 infection

\begin{tabular}{|c|c|c|}
\hline & Mild to moderate infection & Critically ill (intensive care) \\
\hline Clinical picture & $\begin{array}{l}\text { - Asymptomatic } \\
\text { - Mild flu-like symptoms } \\
\text { - Fever - mild to moderate } \\
\text { - Adequate oral intake of food and liquids } \\
\text { - Normal sensorium }\end{array}$ & $\begin{array}{l}\text { - } \text { Pneumonia } \\
\text { - Acute lung injury, ARDS } \\
\text { - Septic shock } \\
\text { - Multiorgan dysfunction } \\
\text { - Acute cardiac injury }\end{array}$ \\
\hline Monitoring & $\begin{array}{l}\text { - Frequent blood glucose monitoring (pre-meal/post-meal) } \\
\text { - Check ketones if blood glucose persistently high } \\
\text { - Periodic assessment of clinical status } \\
\text { - Target blood glucose: pre-meal <140 mg/dL, random <180 mg/dL }\end{array}$ & $\begin{array}{l}\text { - Blood glucose monitoring } 1-2 \text { hourly } \\
\text { - Target blood glucose } 140-180 \mathrm{mg} / \mathrm{dL} \\
\text { - Urine and serum ketones } \\
\text { - } \text { Arterial blood gas } \\
\text { - Other investigations as prescribed by intensive care team }\end{array}$ \\
\hline $\begin{array}{l}\text { Anti-diabetic } \\
\text { medications }\end{array}$ & $\begin{array}{l}\text { - } \text { - Don continue pre-existing stable anti-diabetic medications } \\
\text { is reduced } \\
\text { - Discontinue metformin and SGLT2 inhibitors if there is any evidence of } \\
\text { deterioration (vomiting, dehydration or organ dysfunction) } \\
\text { - GLP-1 RAs may further reduce appetite - consider to } \\
\text { discontinue temporarily } \\
\text { - DPP4 inhibitors can be continued as they are well tolerated and not } \\
\text { contraindicated if there is renal impairment }\end{array}$ & - Stop all oral antidiabetic agents as well GLP-1 RAs \\
\hline Insulin & $\begin{array}{l}\text { - Insulin dose titration of ongoing insulin therapy as per blood glucose } \\
\text { record - correction bolus if required } \\
\text { - Insulin initiation in case of persistent hyperglycaemia or any } \\
\text { deterioration in clinical condition } \\
\text { - Basal bolus insulin regimen }\end{array}$ & $\begin{array}{l}\text { - Intravenous insulin infusion } \\
\text { - Switch to basal bolus insulin regimen after clinical improvement and } \\
\text { once adequate oral intake begins } \\
\text { - Discharge on insulin with instructions for home monitoring and } \\
\text { self-titration of doses }\end{array}$ \\
\hline
\end{tabular}

ARDS = acute respiratory distress syndrome; DPP4 = dipeptidyl-peptidase 4; GLP-1 RAS = glucagon-like peptide 1 receptor agonists; SGLT2 = sodium-glucose co-transporter-2.

In vitro exposure of alveolar epithelial cells to high glucose concentrations was shown to increase viral replication..$^{43}$ Hyperglycaemia also impairs immune response and organ function and may increase the risk of acute lung injury. This calls for a need to ensure adequate glycaemic control in people with diabetes who are diagnosed with COVID-19. However, COVID-19 infection itself impacts glycaemic control in several ways.

1. Worsening of glycaemic control due to the infection, stress response (secretion of counter-regulatory hormones) and inflammation. Cytokine storm may cause significant insulin resistance, resulting in high insulin dose requirements.

2. Worsening of glycaemic control due to the medications used to treat complications in sick patients, such as glucocorticoids, inotropes and intravenous dextrose-containing fluids. Glucocorticoids are often used in the management of severe acute respiratory illness and they can cause new-onset hyperglycaemia or worsening of pre-existent hyperglycaemia.

3. Inadequate oral intake of carbohydrates and fluids due to fever, vomiting, diarrhoea or altered sensorium.

4. Increased risk of dehydration, volume depletion and ketoacidosis, especially in those with type 1 diabetes or patients on sodium-glucose co-transporter-2 (SGLT2) inhibitors.

5. Direct diabetogenic effect of SARS-COV-2. ACE2 is expressed in pancreatic islets and it needs to be determined if the virus can directly damage islet cells.

6. Tocilizumab, an IL-6 blocking antibody, is being evaluated for management of cytokine storm. Due to its anti-inflammatory effects, tocilizumab has been shown to improve insulin sensitivity; ${ }^{; 8}$ however, tocilizumab reduced glucagon-like peptide-1 (GLP-1) secretion in response to a meal. ${ }^{\circ}$ In addition, hyperglycaemia may reduce the clinical efficacy of tocilizumab, possibly due to higher IL-6 levels. ${ }^{70}$
The management of hyperglycamia in patients with COVID-19 and diabetes follows the general principles of diabetes care during acute illness (Table 2). ${ }^{71}$ New onset stress hyperglycaemia may occur and therefore, all sick patients should be monitored regularly for hyperglycaemia. There is a need to maintain good hydration and optimal nutrition, as well as more frequent blood glucose monitoring and titration of antidiabetic therapy. Individualised blood glucose targets and treatment strategies should be formulated in accordance with clinical classification, complications, age, nutritional status and underlying comorbid conditions. Patients who are asymptomatic or have mild symptoms and are able to eat adequately can continue on previous antidiabetic medication with advice to frequently monitor blood glucose and contact the physician if there is any worsening of symptoms or glycaemic control. ${ }^{72}$

In patients with high-grade fever, vomiting, mild respiratory symptoms, etc., drugs such as metformin and SGLT2 inhibitors need to be discontinued. Metformin may increase the risk of lactic acidosis in patients who have renal or hepatic dysfunction, while SGLT2 inhibitors can worsen hypovolaemia, or lead to acute renal injury or diabetic ketoacidosis.72 The dose of sulfonylureas may need to be titrated/reduced as per caloric intake, or if chloroquine or hydroxychloroquine are being prescribed. GLP-1 receptor agonists may reduce appetite and may be temporarily discontinued. DPP4 inhibitors are usually well tolerated and can be continued even in the setting of impaired renal function. ${ }^{73}$ Pioglitazone can cause fluid retention and worsen pulmonary manifestations. Insulin initiation should not be delayed in patients with significant hyperglycaemia, sick patients, those with pneumonia or organ dysfunction, or patients on glucocorticoids. Ideally, insulin should be initiated as a basal bolus injection protocol and titrated according to blood glucose monitoring. The targets for blood glucose in 
non-critically ill patients are those recommended for the management of in-patient hyperglycaemia - premeal $<140 \mathrm{mg} / \mathrm{dL}(<7.8 \mathrm{mmol} / \mathrm{L})$ and random $<180 \mathrm{mg} / \mathrm{dL}(<10.0 \mathrm{mmol} / \mathrm{L}){ }^{.71}$

Patients with severe disease or those who are critically ill require ICU admission, and should be started on intravenous insulin infusion and gradually switched to subcutaneous basal bolus insulin regimens as the clinical picture improves. In general, blood glucose is maintained between 140-180 mg/dL (7.8-10.0 mmol/L) in the ICU, though more liberal targets may be advisable if the risk of hypoglycaemia outweighs the benefits of intensive control. ${ }^{71}$ Following recovery, patients can be discharged on insulin with clear instructions for dose titration based on SMBG.

Patients with type 1 diabetes can continue on previous basal bolus insulin or continuous subcutaneous insulin infusion regimen with frequent SMBG and monitoring of urine ketones. They should be instructed on maintenance of good hydration, sick-day guidelines, and management of hypoglycaemia. Hyperglycaemia can be managed in stable patients with correction doses of rapid-acting insulin. Those with moderate-to-severe illness should be managed in hospital with intravenous or subcutaneous insulin as per the clinical condition.

The use of chloroquine or hydroxychloroquine for the treatment of COVID-19 is a highly debated area. Despite only empirical - and somewhat conflicting - evidence, these drugs have found their way into most institutional guidelines, pending research. ${ }^{74}$ While the rationale for the use of these agents is beyond the purview of this article, it is important to remember that patients with diabetes should be monitored carefully when prescribed these agents. ${ }^{75}$ Hydroxychloroquine raises intracellular $\mathrm{pH}$, resulting in inactivation of the enzyme insulinase that is responsible for degradation of insulin. In addition, it also improves insulin sensitivity and has clinically meaningful glucose-lowering activity. The risk of hypoglycaemia may be increased in patients on insulin or sulphonylureas.

Chloroquine and hydroxychloroquine can cause QTC prolongation. Therefore, a baseline electrocardiogram (ECG) should be conducted and caution is needed when co-prescribing these drugs with other agents that may cause QTC prolongation (azithromycin, teneligliptin, ondansetron, antiarrhythmics, antidepressants, antipsychotics and moxifloxacin). ${ }^{74}$ Monitoring of blood glucose, ECG, complete blood count, serum electrolytes, hepatic and renal functions should be considered. These drugs are contraindicated in individuals with prolonged QTC interval, retinopathy, maculopathy, recent myocardial infarction, porphyria, glucose-6-phosphate dehydrogenase deficiency, or history of drug hypersensitivity. ${ }^{74}$

The long-term impact of COVID-19 infection on the cardiometabolic health of people with diabetes needs to be determined on long-term follow-up.

\section{Management of pregnancy with diabetes during the COVID-19 pandemic}

Pregnant women with pre-existing diabetes or gestational diabetes mellitus form a special group requiring intensive care and frequent monitoring. Pregnancy predisposes women to more severe viral respiratory infections due to physiological changes in immune and cardiopulmonary systems. ${ }^{76}$ Previous experience with SARS and MERS suggests that these acute respiratory syndromes were associated with more severe disease and increased risk of miscarriage, preterm delivery, foetal growth retardation and maternal mortality. ${ }^{77}$ While this cannot be extrapolated to COVID-19, some case series have reported preterm delivery and foetal distress in women with COVID-19.78 There is a high risk of transmission to the newborn due to close contact.76 $\mathrm{A}$ recent report also suggests possible vertical transmission from a mother with severe COVID-19 infection and diabetes. ${ }^{79}$

Pregnant women with diabetes are already at an increased risk of adverse maternal and foetal outcomes. Small case series of pregnant women with COVID-19 have suggested that the presence of gestational diabetes or gestational hypertension did not increase the risk of life-threatening infection in the mother. ${ }^{78}$ While there are currently no large studies on the impact of COVID-19 infection during pregnancy with diabetes, it can be safely assumed that they form a vulnerable group. The risk is further increased because of the need for frequent healthcare visits creating challenges in providing continued safe care.

There exists international consensus that screening for diabetes during pregnancy is essential. During the pandemic, performing oral glucose tolerance tests may pose challenges. The Society of Obstetrics and Gynecology, Canada, has issued a temporary alternative strategy to screen for gestational diabetes using glycosylated haemoglobin (HDA1C) during the COVID-19 pandemic to reduce the risk of infection. ${ }^{80}$ However, screening for gestational diabetes with HbA1C has its own shortcomings, in that reference ranges for $\mathrm{HbA} 1 \mathrm{c}$ have not been defined during pregnancy.

As per the recent guidelines from the International Federation of Gynecologists and Obstetricians, the management of diabetes with pregnancy should follow established protocols and patients should be treated with insulin if medical nutrition therapy and lifestyle modification alone is inadequate. ${ }^{76}$ Tight glycaemic control is an absolute prerequisite to ensure healthy outcomes, and women should be instructed to maintain records of SMBG. Telemedicine facilities offer a good platform for the remote monitoring of their diabetes management. ${ }^{81}$ For in-person visits, adequate precautions are needed to minimise the risk of cross-infection. Pregnant women with diabetes also require psychological and emotional support from their care providers, especially during this time.

\section{Emerging social challenges for women}

Women may be more vulnerable during pandemics due to a variety of reasons that go beyond the risk of infection, such as exacerbation of pre-existing social injustice and health inequality, ${ }^{82}$ with women in LMICS being even more vulnerable. Increased domestic responsibilities, along with professional responsibilities, may take a greater toll on them. Mass school closure might have a differential effect as women provide most of the childcare and care within families, with the consequence of limiting their work and economic opportunities. Those who are poor, working in service jobs, and those without paid leave are especially vulnerable. Travel restrictions can also cause financial challenges for female domestic workers. Reports of domestic violence during this period of quarantine are also on the rise..$^{83}$ In addition, the pandemic is likely to have longstanding economic consequences, which may put further strain on women's health and women's rights.

Women form $70 \%$ of workers in the health and social sector, work longer hours, along with domestic responsibilities, emphasising the gendered nature of the workforce and the risk they incur. ${ }^{37}$ They also earn $11 \%$ less than men in the same field. ${ }^{37}$ In South East Asia, the percentage of female and male physicians is $39 \%$ and $61 \%$, respectively; whereas the percentage of female and male nurses is $79 \%$ and $21 \%$, respectively. ${ }^{37}$ 
As health systems become stretched, many people with COVID-19 will need to be cared for at home, adding to women's workloads and increasing the risk of them becoming infected. Women are less likely than men to have power in decision-making, compounded by their inadequate access to healthcare and insufficient financial resources to travel to hospitals for check-ups. Therefore, it is very important to formulate an action plan to ensure community education, empowerment and participation, to ensure availability of essential services and medications, promote transparency and accountability, and foster international cooperation.

\section{Conclusion}

COVID-19 has created significant challenges for healthcare delivery, especially in people with chronic cardiometabolic disorders, as these individuals are at an increased risk of morbidity related to COVID-19. Women with diabetes form a vulnerable group, as they often receive suboptimal diabetes care and support, even though they have a high burden of comorbidities and complications. While there are challenges in healthcare delivery during the pandemic, cardiometabolic care cannot be compromised. This calls for exploring new avenues of healthcare delivery, such as telemedicine. Pregnant women with diabetes should continue to receive quality care for optimal outcomes. The management of hyperglycaemia during COVID-19 infection is important to reduce morbidity and mortality from the infection.

Recognising the extent to which disease outbreaks affect women and men differently, especially those with underlying health risks, is critical for creating effective policies and interventions to promote gender equity goals. Gendered implications of quarantine need to be recognised. A gender analysis is warranted to mitigate risk in the current pandemic and to prevent women from paying the price, both now and in the future. $\square$

\section{Article highlights}

- Gender differences in epidemiology and the gendered impact of the COVID-19 pandemic need to be evaluated

- Diabetes is linked to a greater risk of morbidity and mortality associated with COVID-19

- Women with diabetes are an especially vulnerable group as they often receive suboptimal diabetes care and support, even though they have a high burden of comorbidities and complications

- Pregnant women with diabetes should continue to receive quality care for optimal outcomes

- The management of hyperglycaemia during COVID-19 infection is important to reduce morbidity and mortality from the infection

- While there are challenges in healthcare delivery during the pandemic, cardiometabolic care cannot be compromised. This calls for exploring new avenues of healthcare delivery, such as telemedicine

- The psychological health of women also needs special consideration during this time

1. Zhu N, Zhang D, Wang W, China novel coronavirus investigating and research team, et al. a novel coronavirus from patients with pneumonia in china, 2019. N Eng/ J Med. 2020;382:727-33.

2. Shang J, Ye G, Shi K, et al. Structural basis of receptor recognition by SARS-COV-2. Nature 2020:581:221-4.

3. Guan WJ, Liang WH, Zhao Y, et al. Comorbidity and its impact on 1590 patients with COVID-19 in China: a nationwide analysis. Eur Respir J. 2020;55:2000547.

4. Li B, Yang J, Zhao F, et al. Prevalence and impact of cardiovascular metabolic diseases on COVID-19 in China. Clin Res Cardiol. 2020:109:531-8.

. Emami A, Javanmardi F, Pirbonyeh N, Akbari A. Prevalence of underlying diseases in hospitalized patients with COVID-19: systematic review and meta-analysis. Arch Acad Emerg Med. 2020;8:e35

6. Yi Y, Lagniton PNP, Ye S, et al. COVID-19: what has been learned and to be learned about the novel coronavirus disease. Int J Biol Sci. 2020;16:1753-66.

7. Kautzky-Willer A, Harreiter J, Pacini G. Sex and gender differences in risk, pathophysiology and complications of type 2 diabetes mellitus. Endocr Rev. 2016:37:278-316.

8. Suresh N, Thankappan KR. Gender differences and barriers women face in relation to accessing type 2 diabetes care: a system ace in relation to accessing type 2 diabetes care:

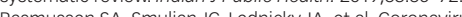
disease 2019 (COVID-19) and pregnancy what obstetricians disease 2019 (COVD-19) and pregnancy: What obstetriciant

10. Lašaitè L, Ostrauskas R, Žalinkevičius $R$, et al. Diabetes distress in adult type 1 diabetes mellitus men and women with disease onset in childhood and in adulthood. J Diabetes Complications. 2016;30:133-7.

11. Bradbury-Jones C, Isham L. The pandemic paradox: the consequences of COVID-19 on domestic violence. J Clin Nurs. 2020; doi:10.1111/jocn.15296 [Epub ahead of print].

12. Chen N, Zhou M, Dong X, et al. Epidemiological and clinical characteristics of 99 cases of 2019 novel coronavirus pneumonia in Wuhan, China: a descriptive study. Lancet. 2020:395:507-13.

13. Zhang J, Litvinova $M$, Wang $W$, et al. Evolving epidemiology and transmission dynamics of coronavirus disease 2019 outside Hubei province, China: a descriptive and modelling study. Lancet Infect Dis. 2020:20:793-802.

14. Zhang JJ, Dong $X$, Cao $Y$, et al. Clinical characteristics of 140 patients infected with SARS-CoV-2 in Wuhan, China. Allergy. 2020;75:1730-4

15. Epidemiology Working Group for NCIP Epidemic Response Chinese Center for Disease Control and Prevention. [The epidemiological characteristics of an outbreak of 2019 novel coronavirus diseases (COVID-19) in China]. Zhonghua Liu Xin Bing Xue Za Zhi. 2020;41:145-51.

16. Korean Society of Infectious Diseases, Korean Society of Pediatric Infectious Diseases, Korean Society of Epidemiology, et al. Report on the epidemiological features of coronavirus disease 2019 (COVID-19) outbreak in the Republic of Korea from
January 19 to March 2, 2020. J Korean Med Sci. 2020;35:e112. Ruan Q, Yang K, Wang W, et al. Clinical predictors of mortality due to COVID19 based on an analysis of data of 150 patients from Wuhan, China. Intensive Care Med. 2020;46:846-8.

18. Yang $X, Y u Y, X u \perp$ et al Clinical course and outcomes of critically ill patients with SARS-COV-2 pneumonia in Wuhan, China: a single-centered, retrospective, observationt study. China: a single-centered, retrospectiv

19. McMichael TM, Currie DW, Clark S, et al. Epidemiology of COVID-19 in a long-term care facility in King county, Washington. N Engl I Med. 2020:382:2005-11.

20. Yadavar S. How COVID-19 has affected men more, figures of both infected cases and deaths show, 2020. Available at: https://theprint.in/health/how-covid-19-has-affected-menmore-figures-of-both-infected-cases-and-deaths-show/396758/ (accessed 4 June 2020)

21. Cheng $\mathrm{H}$, Wang Y, Wang G-Q. Organ-protective effect of angiotensin-converting enzyme 2 and its effect on the prognosis of COVID-19. J Med Virol. 2020;92:726-30.

22. Jia HP, Look DC, Hickey M, et al. Infection of human airway epithelia by SARS coronavirus is associated with ACE2 expression and localization. Adv Exp Med Biol. 2006;581:479-84

23. Danser AHJ, Epstein M, Batlle D. Renin-angiotensin system blockers and the COVID-19 pandemic: at present there is no evidence to abandon renin-angiotensin system blockers Hypertension. 2020;75:1382-5.

24. Hanff TC, Harhay MO, Brown T, et al. Is there an association between COVID-19 mortality and the renin-angiotensin system - a call for epidemiologic investigations. Clin Infect Dis. 2020;71:870-4

25. Xie X, Chen J, Wang X, et al. Age- and gender-related difference of ACE2 expression in rat lung. Life SCi. 2006;78:2166-71.

26. Zhao Y, Zhao Z, Wang Y, et al. Single-cell RNA expression profiling of ACE2, the receptor of SARS-COV-2. Am I Respir Crit Care Med. 2020:202:756-9.

27. Zhang P, Zhu L, Cai J, et al. Association of inpatient use of angiotensin converting enzyme inhibitors and angiotensin II receptor blockers with mortality among patients with II receptor blockers with mortality among patients
hypertension hospitalized with COVID-19. Circ Res. 2020:126:1671-81.

28. Baratchian M, McManus J, Berk M, et al. No evidence that androgen regulation of pulmonary TMPRSS2 explains sex-discordant COVID-19 outcomes. bioRxiv. 2020; do: 10.1101/2020.04.21.051201 [Preprint ahead of publication].

29. Shastri A, Wheat J, Agrawal S, et al. Delayed clearance of SARS-CoV2 in male compared to female patients: High ACE2 expression in testes suggests possible existence of gender-specific viral reservoirs. medRxiv. 2020; doi: 10.1101/2020.04.16.20060566 [Preprint ahead of publication].

30. Montastruc F, Romano C, Montastruc IL, et al. Pharmacologica characteristics of patients infected with SARS-COV-2 admitted to intensive care unit in South of France. Therapie. 2020;75:381-4.
31. Zhang $X, Y u J$, Pan $L Y$, Jiang HY. ACEI/ARB use and risk of infection or severity or mortality of COVID-19: a systematic review and meta-analysis. Pharmacol Res. 2020;158:104927.

32. Mackey K, King VJ, Gurley S, et al. Risks and impact of angiotensin-converting enzyme inhibitors or angiotensin-receptor blockers on SARS-COV-2 infection in adults. Ann Intern Med. 2020;73:195-203.

33. De Abajo F, Rodriguez-Martin S, Lerma V, et al. Use of renin-angiotensin-aldosterone system inhibitors and risk of COVID-19 requiring admission to hospital: a case-population study. Lancet. 2020:395:1705-14.

34. Vardavas $\mathrm{Cl}$, NKitara K. COVID-19 and smoking: a systematic review of the evidence. Tob Induc Dis. 2020;18:20.

35. Cai H. Sex differences and smoking predisposition in patients with COVID-19. Lancet Respir Med. 2020;8:e20

36. Leung JM, Yang CX, Tam A, et al. ACE-2 expression in the small airway epithelia of smokers and COPD patients: implications for COVID-19. Eur Respir J. 2020;55:2000688.

37. Boniol M, Mclsaac M, Xu L, et al. Gender equity in the health workforce: analysis of 104 countries. 2019. Available at: https://apps. who int/iris/bitstream/handle/10665/311314/WHOHIS-HWF-Gender-WP1-2019.1 nng df (accessed 4 June 2020).

38. Frydrych $\mathrm{LM}$, Bian $\mathrm{G}$, $\mathrm{O}^{\prime} \mathrm{L}$ one $\mathrm{DE}$, et al. Obesity and type 2 diabetes mellitus drive immune dysfunction, infection development, and sepsis mortality. J Leukoc Biol. 2018:104:525-34.

39. Bloomgarden ZT. Diabetes and COVID-19. J Diabetes. 2020;12:347-8

40. Liu C, Li Y, Guan T, et al. ACE2 polymorphisms associated with cardiovascular risk in Uygurs with type 2 diabetes mellitus. Cardiovasc Diabetol. 2018;17:127.

41. Gupta R, Ghosh A, Singh AK, Misra A. Clinical considerations for patients with diabetes in times of COVID-19 epidemic. Diab Met Synd. 2020;14:211-12.

42. Wang A, Zhao W, Xu Z, Gu J. Timely blood glucose management for the outbreak of 2019 novel coronavirus disease (COVID-19) is urgently needed Diabetes Res Clin Pract. 2020:162:108118.

43. Guo W Li M, Dong Y et al. Diabetes is a risk factor for the progression and prognosis of COVID-19. Diabetes Metab Res progression and prognosis of COVID-19. Diabetes Metab Res Rev. 2020; dol: 10.1002/dmrr.3319 (Epub ahead of print.

4. Centers for Disease Control and Prevention (CDC). CDC COVID-19 Response Team. Preliminary estimates of the
prevalence of selected underlying health conditions among patients with coronavirus disease 2019 - United States, February 12-March 28, 2020. Available at: www.cdc.gov/mmwr/ volumes/69/Wr/mm6913e2.htm (accessed 4 June 2020)

45. Remuzzi A, Remuzzi G. COVID-19 and Italy: what next? Lance 2020;395:1225-8

46. Dasgupta K, Da Costa D, Pillay S, et al. Strategies to optimize participation in diabetes prevention programs following gestational diabetes: a focus group study. PLOS One. 2013:8:e67878.

47. Nicklas JM, Zera CA, Seely EW, et al. Identifying postpartum intervention approaches to prevent type 2 diabetes in women 
with a history of gestational diabetes. BMC Pregnancy Childbirth. 2011:11:23.

48. Pamungkas RA, Chamroonsawasdi K, Vatanasomboon P. A systematic review: family support integrated with diabetes self-management among uncontrolled type $\|$ diabetes mellitus patients. Behav Sci (Basel). 2017;7:62.

49. Cappuccio FP, Miller MA. Sleep and cardio-metabolic disease Curr Cardiol Rep. 2017;19:110

50. Irwin MR, Opp MR. Sleep health: reciprocal regulation of sleep and innate immunity. Neuropsychopharmacology 2017:42:129-55

51. Portnoy J, Waller M, Elliott T. Telemedicine in the era of COVID-19. J Allergy Clin Immunol Pract. 2020;8:1489-91.

52. MCDonnell ME. Telemedicine in complex diabetes management. Curr Diab Rep. 2018;18:42.

53. Board of Governors in Supersession of the Medical Council of India, Appendix 5 of the Indian Medical Council (professional conduct, etiquette and ethics) Regulations. 2020. Available at: www.mohfw.gov.in/pdf/Telemedicine.pdf (accessed 4 June 2020).

54. Ghosh A, Gupta R, Misra A. Telemedicine for diabetes care in India during COVID19 pandemic and national lockdown period: guidelines for physicians. Diabetes Metab Syndr. 2020;14:273-6.

55. Fisher-Hoch SP, Mathews $C E$, McCormick JB. Obesity, diabetes and pneumonia: the menacing interface of non-communicable and infectious diseases. Trop Med Int Health. 2013;18:1510-9.

56. Buse JB, Wexler DJ, Tsapas A, et al. 2019 update to: management of hyperglycemia in type 2 diabetes, 2018. A consensus report by the American Diabetes Association (ADA) and the European Association for the Study of Diabetes (EASD). Diabetes Care. 2020:43:487-93.

57. Drucker DJ. Coronavirus infections and type 2 diabetes-shared pathways with therapeutic implications. Endocr Rev. 2020;41:bnaa011.

58. lacobellis G. COVID-19 and diabetes: can DPP4 inhibition play a role? Diab Res Clin Pract. 2020;162:108125.

59. American College of Cardiology. HFSA/ACC/AHA statement addresses concerns re: using RAAS antagonists in COVID-19, 2020. Available at: www.acc.org/latest-in-cardiology/ articles/2020/03/17/08/59/hfsa-acc-aha-statement-addressesconcerns-re-using-raas-antagonists-in-covid-19 (accessed 4 June 2020).

60. European Society of Cardiology. Position statement of the ESC Council on hypertension on ACE-inhibitors and angiotensin receptor blockers, 2020. Available at: www.escardio.org/ Councils/Council-on-Hypertension-(CHT)/News/position- statement-of-the-esc-council-on-hypertension-on-aceinhibitors-and-ang (accessed 4 June 2020).

61. International Society of Hypertension. A statement from the International Society of Hypertension on COVID-19, 2020. Available at: https://ish-world com/news/a/A-statementfrom-the-International-Society-of-Hypertension-on-COVID-19/ (accessed 4 June 2020).

62. Liu N, Zhang F, Wei C, et al. Prevalence and predictors of PTSS during COVID-19 outbreak in China hardest-hit areas: gender differences matter. Psychiatry Res. 2020;287:112921.

63. MCLean CP, Anderson ER. Brave men and timid women? A review of the gender differences in fear and anxiety. Clin Psychol Rev. 2009;29:496-505

64. Duan L, Zhu G. Psychological interventions for people affected by the COVID-19 epidemic. Lancet Psychiatry. 2020;7:300-2.

65. Weaver $\sqcup$, Madhu SV. Type 2 diabetes and anxiety symptoms among women in New Delhi, India. Am J Public Health. 2015;105:2335-40.

66. lacobucci G. COVID-19: diabetes clinicians set up social media account to help alleviate patient's fears. BMJ. 2020;368:m1262.

67. Indian Medical Association. General points for clinics regarding COVID 19, 2020. Available at: www.ima-india.org/ima/pdfdata/ COVID-19/General-points-for-clinics.pdf (accessed 4 June 2020).

68. Castaneda S, Remuzgo-Martinez S, Lopez-Mejias R, et al. Rapid beneficial effect of the IL-6 receptor blockade on insulin resistance and insulin sensitivity in non-diabetic patients with rheumatoid arthritis. Clin Exp Rheumatol. 2019;37:465-73.

69. Ellingsgaard $\mathrm{H}$, Seelig E, Timper K, et al. GLP-1 secretion is regulated by IL-6 signalling: a randomised, placebo-controlled study. Diabetologia. 2020;63:362-73.

70. Marfella R, Paolisso P, Sardu C, et al. Negative impact of hyperglycemia on tocilizumab therapy in COVID-19 patients. medRxiv 2020; doi: 10.1101/2020.04.29.20076570 [Preprint ahead of publication].

71. Umpierrez GE, Hellman R, Korytkowski MT, et al. Management of hyperglycemia in hospitalized patients in non-critical care setting: an endocrine society clinical practice guideline. setting: an endocrine society clinical practic

72. Bornstein SR, Rubino F, Khunti K, et al. Practical recommendations for the management of diabetes in patients with COVID-19. Lancet Diab Endocrinol. 2020;8:546-50.

73. Research Society for The Study of Diabetes in India. RSSDI Guidance for healthcare professionals on COVID-19, 2020. Available at: https://rssdi.in/newwebsite/rssdi-guidance-forhealthcare-professionals-on-covid-19.php

(accessed 4 June 2020).

74. Gupta R, Misra A Contentious issues and evolving concepts in the clinical presentation and management of patients with COVID-19 infection with reference to use of therapeutic and other drugs used in co-morbid diseases (hypertension, diabetes etc). Diabetes Metab Syndr. 2020:14:251-4.

75. Singh AK, singh A, Shaikh A, et al. Chloroquine and hydroxychloroquine in the treatment of COVID-19 with or without diabetes: a systematic search and a narrative review with special reference to India and other developing countries. Diabetes Metab Syndr. 2020;14:241-6.

76. Poon LC, Yang $\mathrm{H}$, Kapur A, et al. Global interim guidance on coronavirus disease 2019 (COVID-2019) during pregnancy and puerperium from FIGO and allied partners: information for healthcare professionals. Int I Gynecol Obstet. 2020;149:273-86

77. Hussein J. COVID-19: what are the implications for sexual and reproductive health and rists

78. Schwartz DA. An analysis of 38 pregnant women with COVID-19, their newborn infants, and maternal-fetal transmission of SARS-CoV-2: maternal coronavirus infections and pregnancy outcomes. Arch Pathol Lab Med. 2020: do:10.5858/arpa 2020-0901-SA [Online ahead of print].

2020;dol:10.5858/arpa.2020-0901-SA [Online ahead of print]. during pregnancy and possible vertical transmission. Am J Perinatol. 2020;37:861-5.

80. Yamamoto JM, Donovan LE, Feig DS, Berger H. Urgent update - temporary alternative screening strategy for gestational diabetes screening during the covid-19 pandemic a joint consensus statement from the Diabetes Canada Clinical Practice Guidelines Steering Committee and the Society of Obstetricians and Gynecologists of Canada, 2020. Available at: https://els-jbs-prod-cdn.jbs.elsevierhealth.com/pb/ assets/raw/Health\%20Advance/journals/jcjd/JCJD_COVID_ guidelines 020420-1585856697530.pdf (accessed 4 June 2020).

81. Ming WK, Mackillop LH, Farmer AJ, et al. Telemedicine technologies for diabetes in pregnancy: a systematic review technologies for diabetes in pregnancy: a systematic

82. Chattu VK, Yaya S. Emerging infectious diseases and outbreaks: implications for women's reproductive health and rights in resource poor settings. Reprod Health. 2020;17:43.

83. Neuman S. Global lockdowns resulting in 'horrifying surge' in domestic violence, UN warns. Available at: www.npr.org sections/coronavirus-live-updates/2020/04/06/827908402/ global-lockdowns-resulting-in-horrifying-surge-in-domesticviolence-u-n-warns (accessed 17 June 2020). 